\title{
EXPERIENCE VALUE OR SATIETY? THE EFFECTS OF THE AMOUNT AND VARIETY OF TOURISTS’ ACTIVITIES ON PERCEIVED EXPERIENCE
}

\section{Carmen Antón}

Associate Professor

Department of Business and Marketing, University of Valladolid

Facultad de Ciencias Económicas y Empresariales

Avenida del Valle Esgueva, 6 - 47011 Valladolid, Spain. e-mail: anton@eco.uva.es.

Tf. 34-83-423413

Fax. 34-83-423899

\section{Carmen Camarero (corresponding author)}

Associate Professor

Department of Business and Marketing, University of Valladolid

Facultad de Ciencias Económicas y Empresariales

Avenida del Valle Esgueva, 6 - 47011 Valladolid, Spain. e-mail: camarero@eco.uva.es.

Tf. 34-83-423332

Fax. 34-83-423899

\section{Marta Laguna}

Associate Professor

Department of Business and Marketing, University of Valladolid

Facultad de Ciencias Sociales, Jurídicas y de la Comunicación

Plaza Alto de los Leones, 1 - 40005 Segovia, Spain. e-mail: martalag@eade.uva.es

Tf. 34-83-423000-2111

Fax. 34-83-423899

\section{Acknowledgment}

This work was supported by the Junta de Castilla y León (Spain) [project references VA112P17 and VA085G18] and by the Ministry of Economy, Industry, and Competitiveness (Spain) [project reference ECO2017-86628-P].

When the paper was submitted, we had not received funding, so no reference is made to the projects in the publication.

This is the accepted version of the manuscript: Antón, C., Camarero-Izquierdo, C., y LagunaGarcía, M. (2018). Experience value or satiety? The effects of the amount and variety of tourists' activities on perceived experience. Journal of Travel Research, 57(7), 920-935. https://doi.org/10.1177/0047287517727366 


\begin{abstract}
:
In recent years, destinations have moved from designing products to focusing on creating experiences that engage and involve the tourist. This study explores the role played by the value of tourist experience and of satiety as mediators between experience intensity and variety as well as future visitor behaviour. Although the intensity and variety of the experience leads tourists to feel their experience has been richer and to appraising it positively, it might also bring unwanted consequences such as a feeling of saturation. The empirical study reveals that the extensiveness of the experience improves the perceived experience value, whereas intensiveness reduces the value and causes satiety in the tourist. Moreover, while the experience value reinforces the intention to return, the intention to recommend and the intensification of the experience, the feeling of satiety, on the other hand, reduces the intention to return and even the intention to recommend the destination
\end{abstract}

Keywords: satiety, tourist experience, experience intensity, extensiveness, behavioural intention 
EXPERIENCE VALUE OR SATIETY? THE EFFECTS OF THE AMOUNT AND VARIETY OF TOURISTS' ACTIVITIES ON PERCEIVED EXPERIENCE

\author{
Abstract \\ Tourist firms and destinations have moved from designing products to focusing on \\ creating experiences that engage and involve the tourist. Although the intensity \\ (intensiveness) and variety of the experience (extensiveness) leads tourists to feel their \\ experience has been livelier and richer and to appraising it positively, it might also bring \\ unwanted consequences such as a feeling of saturation. The present study seeks to \\ explore the role played by the value of said experience and of satiety as mediators \\ between experience intensity and variety as well as future visitor behaviour. The \\ empirical study reveals that the variety of activities improves the perceived experience \\ value, whereas investing too much time reduces the value and causes satiety in the \\ tourist. Moreover, while the experience value reinforces the intention to return, the \\ intention to recommend and the intensification of the experience, the feeling of satiety, \\ reduces the intention to return and recommend.
}

\title{
Keywords
}

Tourist experience, intensity, variety, satiety, behavioural intention 


\section{INTRODUCTION}

Today's clients not only seek to fulfil their basic needs but also to expand their range of consumer choices and situations to a higher level; the level of excitement and experiences. Since the publication of Pine and Gilmore's work (1999), the notion that experiences constitute the essence of consumption has taken root amongst marketing scholars in general and particularly amongst those analysing the tourist industry and market. This is reflected in the many recent studies in the tourist field that have addressed the empirical study of tourist experiences, such as Hosany and Witham (2010), Barnes et al (2014) and Neuhofer et al (2014).

In the area of services, what clients feel and think to a large extent stems from what they do and from the sensations that are aroused when interacting with the product at socalled "touch points" (Meyer and Schwager, 2007). From a tourist perspective, the experience also involves every aspect in terms of direct or indirect contact with what the destination being visited has to offer (Meyer and Schwager, 2007). Individuals forge their experience based on their subjective perception of each moment and situation in which they interact with the place visited or consume the tourist product (Anderson, 2007). Yet, despite the clear link between "what the tourist does, feels, and thinks," few works have focused on exploring the link between these and how the visitors' role as "doers" impacts their experience and future behavioral intentions (Addis and Holbrook, 2001) impacts on their experience and future behaviour. This is the specific context in which the current work is framed: what happens when a tourist is extremely active and squeezes out all the possibilities a destination has to offer? What are the consequences on their experience and future intentions?

The desire of tourist firms and destinations to maximise visitor economic impact has led them to devise strategies aimed at increasing not only tourist numbers but also the 
frequency of the trip, the length of the stay and the amount spent so as to thus enhance profitability (Mook and Iverson, 2000). However, the impact of the objective or quantitative dimension of the experience on future intentions (intention to return or to intensify the visit) might prove ambiguous. A more intense visit might provide the visitor with a chance to gain a fresh and more comprehensive perspective of the place visited, encouraging them to repeat the experience in future (Petrick, 2004). On the other hand, tourists who invest more time, money and effort might get the feeling of having fully exploited all the possibilities the destination has to offer and so discard it as a future tourist option. Whilst it is true that active tourists may have more intense experiences in different environments, too much time or money invested in a particular destination may lead to satiety.

In the current study, we propose that the tourist experience involves two dimensions: the objective experience (tourists' activity) and the subjective experience (the experience value). According to Hoeffler et al. (2013), the objective experience can be measured in terms of intensiveness (amount of activity) and extensiveness (scope of the activities). Both the intensiveness and extensiveness of activities can trigger a positive evaluation of the experience. Yet, while extensiveness can reduce satiety (or the psychological perception of weariness resulting from the activities undertaken), intensiveness can increase the perception of satiety. Tourist experience and satiety exert a differing impact on their future intentions. Remembering positive experiences boosts the intention to repeat the destination and to recommend (Chen and Chen, 2010; Hosany and Witham, 2009, 2010; Oh et al., 2007; Prebensen et al., 2014; Williams and Soutar, 2009) or to intensify the visit and maintaining interest in the destination or type of activity (De Rojas and Camarero, 2008), whereas satiety can, however, have a negative impact on future intentions. 
Our study attempts to address the consequences of the amount and variety of tourists' activity and to consider the issue of satiety. To the best of our knowledge, few studies have explored the role of satiety as a negative consequence of a major investment in a destination. In the current study, we show evidence of the mediating role of the experience value and the perceived satiety between the objective experience and the tourist's future behaviour. Enjoying a greater number of tourist activities and products may provide an experiential reward in itself that makes individuals more willing to talk about what they have learnt and experienced (Csikszentmihalyi, 2000) and ready to repeat (Petrick, 2004). Our study, however, highlights that only if the activity is varied will the experience be valued positively, will satiety be reduced, and will there be future loyalty. Contrastingly, a major investment in terms of time will cause satiety, reduce the value of the experience and lead to tourists being less likely to repeat or even recommend the destination.

\section{THEORETICAL AND CONCEPTUAL}

\section{BACKGROUND}

\subsection{The experience economy and the tourist experience}

The experience economy approach recognizes experiences as a distinct economic offering. Pine and Gilmore $(1998,1999)$ pioneered this approach when claiming that companies need to shift their business focus from offering services (service economy) to creating unforgettable memories. These memories become a new product in itself (Oh et al., 2007). Pine and Gilmore (1999, p. 12) defined experience as "events that engage individuals in a personal way". Said authors establish four areas of the value of the experience depending on the individual's degree of involvement and engagement: entertainment, education, aesthetics and escapism. They point out that many of the most 
enriching experiences merge aspects of all four. Entertainment is the result of passively absorbing experiences through the senses, although there is less relational connection with the event, since it is observed from outside. Education requires active participation but no close connection to the event. Aesthetic experiences imply higher levels of customer immersion but low levels of customer participation. Finally, escapism is an imaginative activity requiring active participation and a high degree of immersion in an event.

The experience economy concept has been introduced in tourism research in order to interpret tourist experiences (Hosany and Witham, 2009; Mehmetoglu and Engen, 2011; Oh et al., 2007; Park et al., 2010). Tourists seek unforgettable and memorable experiences, and these determine the value of the destination visited (Oh et al., 2007; Song et al., 2015). As Oh et al. (2007) indicate, “everything tourists go through at a destination can be experience, be it behavioural or perceptual, cognitive or emotional". In this line, we distinguish two dimensions of the experience, the objective (or tourist's behaviour) and the subjective (or tourist's perception). The subjective dimension in turn involves cognitive and emotional aspects.

The objective dimension of the tourist experience. The objective dimension of the experience reflects the quantitative aspects related to the tourist's consumption at the destination. One aspect of the experience is the mere exposure to the stimuli (Hoeffler et al., 2013). In the tourist context, this dimension has been evaluated in terms of visit intensity. Beerli and Martín (2004) define visit intensity as the individual's level of interaction with the destination and measure it through the number of places of interest the individual is personally familiar with. In a similar vein, Antón et al. (2014) posit a quantitative measure reflecting the objective and behavioural component of the 
experience, measured through the duration of the stay and the amount spent. A longer stay in terms of days and amount spent might enable the visitor to forge a closer relationship with the destination and enjoy more activities and tourist products. All of these evaluations underscore the extent of the activity but neglect the issue of variety. Hoeffler et al. (2013) refine the objective experience into two sub-dimensions: intensiveness and extensiveness. Intensiveness is the "amount of frequency with which a person has been exposed to a product category". For instance, a tourist who has spent many days in the same destination has accumulated a high intensiveness of experience. Extensiveness is the "breadth or the variety of exposure a person has accumulated in a product environment". In the context of tourism, it involves the variety of activities performed during the visit to a destination.

The subjective dimension of the tourist experience. The tourist experience cannot be properly understood without taking into account its subjective dimension: the experience value. The subjective dimension refers principally to the value and emotional aspect the tourist attributes to the activities undertaken as a whole. In a tourism context, Prebensen et al., (2013) define experience value as the benefits tourists perceive from a journey and from their stay at a particular destination, including assets or resources which they and other tourists as well as the host bring to the process of cocreating experiences. The experience value is thus an individual perception, and is relativistic and comparative (Prebensen and Xie, 2017). Moreover, the experience value perception involves the tourist taking part in creating experience value. As pointed out by Carballo et al., (2015, p.71) when tourists travel, the real journey is an interior one and depends on the impact caused by their subjective and personal perception. In this regard, Jaakkola et al. (2015) define the experience with a service as the individual's 
subjective response to the elements of a service and which emerges during the purchase or use process or through imagination or memory.

With regard to measuring the value of an experience, reference must be made to the pioneering work of Pine and Gilmore (1998). Pine and Gilmore's concept and model (the four realms of experience) have proved suitable for measuring the benefits of tourist activity and have been applied and validated in a number of studies in the tourism field (Hosany \& Witham, 2009; Mehmetoglu \& Engen, 2011; Oh, Fiore, \& Jeoung, 2007; Park, Oh, \& Park, 2010; Song et al., 2015). This model fits in with the concept of Prebensen et al's. (2014, p. 101) tourism experience value, specifically when they indicate that the tourism experience may be explained as a result of a set of physical, emotional, spiritual and/or intellectual impressions. This concept of tourism implies that the experience value involves cognitive and emotional aspects. Arnould and Price (1993) note that extraordinary experiences are those characterised by high levels of emotional intensity. Yet, certain authors defend the idea that in addition to the emotional side, experiences also involve a cognitive component (Oh, Fiore and Jeoung; 2007; Carlson, 1997; Walls et al, 2011).

Based on the above proposals, in the present work we distinguish two main components of the experience value, the cognitive and the emotional. The cognitive component refers to physical and intellectual impressions, which we identify as attainment and learning, while the emotional component refers to emotional and spiritual impressions, which we specify as escapism and fantasy.

(1) Attainment is seen as the perception that the investment made has been capitalised on and rewarded and is closely linked to the value tourists attribute to their experience at the destination (Laing et al. 2014; Prebensen et al. 2013). It is 
principally a cognitive and rational evaluation of the experience, in terms of effectiveness based on the belief that the activity has proven both full and beneficial.

(2) Learning is the tourist's perception of the experience having proved enriching and instructive in the sense that the trip has provided them with or taught them something new. In the case of tourism, it is a key element in that one of the main reasons for travelling is precisely to learn and acquire knowledge about a destination (Ali et al. 2014; Holbrook, 1994; Hossany and Witham, 2010; Oh et al. 2007; Pine and Gilmore, 1999; Yoon and Uysal, 2005)

(3) Escapism indicates the tourist's feeling of having got away from it all for a time. This aspect is emotional and also reflects one of the reasons why people engage in tourism, namely leisure and to escape the daily grind (Oh, et al. 2007; Otto and Ritchie, 1996; Yoon and Uysal, 2005).

(4) Fantasy is the reaction to the stimuli through the imagination. It is also an emotional element implying the destination's capacity to create unique feelings and emotions in the visitor. In the prior literature concerning tourism it was not included as a separate dimension of experience although Holbrook and Hirschman (1982) state that it is an important experience of hedonic consumption, and $\mathrm{Wu}$ and Holsapple (2014) consider it a determinant factor of consumption in online gaming.

\subsection{From the objective experience to the experience value}

Much of the literature addressing consumer experience has focused on exploring which aspects shape memorable, real, singular and significant experiences in various contexts, such as experience in online purchasing (Mathwick et al., 2001), brand experience (Brakus et al., 2009) or experience in retail establishments (Verhoef et al., 2009). 
In the case of tourism, works examining the drivers of experience (see Kim et al., 2012, Kim, 2014) tend to merge the features of the destination (infrastructure, accessibility, local culture, activities and events, service quality, hospitality, physiography and climate, safety, etc.) a tourist's traits (personal significance, prior knowledge) and tourist activity (involvement, social interaction, learning, relaxation).

The present work focuses on the influence of the tourist's activity (objective experience) in the perceived value of the experience. Although tourist experience stems from what the visitors do and feel at the destination and therefore from their experience when buying, consuming and coming into direct contact with tourist amenities (Anderson, 2007; Holbrook, 2000; Laing, et al., 2014; Lewis and Chambers, 2000; Meyer and Schwager, 2007; Verhoef et al. 2009) few studies have explored the impact of tourists' activities "as doers", particularly with regard to the intensiveness or extensiveness of their activity, on how they evaluate their experience. There remains much to be explored concerning how the intensity with which visitors interact with the various stimuli (products, facilities) can affect or influence their perceptions and behaviour. Only a few works link the activities to the experience. As Laing, et al. (2014) point out, although experiences involve a very strong personal and subjective component, they also depend on which factors tourists might encounter at the place visited. In this sense, the research undertaken by Mook and Iverson (2000) reports that the "heavy spenders" spend more time at the destination and spend more in all the various categories (meals, tourism transportation, entertainment, shopping, prepaid expenditure) in an effort to fully exploit the visit. Lee and Beeler (2009) and Lu et al. (2015) find that tourist involvement and participation in activities and events has a positive impact on tourists' experience and on their appraisal of the destination's image. 
In this respect, it could be felt that tourists who invest more time and money in the destination (high intensiveness) will get the feeling of having derived more from the visit. This greater intensity is thus more likely to have enabled them to enjoy a learning, escapism or fantasy experience.

Likewise, tourists who undertake a wider range of activities (high extensiveness) will have a greater chance to benefit from the visit and to learn, to have more opportunities to engage in escapism and a greater incentive to indulge in fantasy. The urge to explore, seek out new things and fresh stimuli and indulge their curiosity -motivations that are innate to most visitors- might increase the number of things which visitors feel they must do and see. This greater variety in their experience might not only lead to a heightened feeling of having learnt while doing things, consuming products and engaging in experiences (learning by doing) but might also create a feeling of not having "just stood there" but of having got more out of their stay and of having escaped from the daily routine. Thus,

\section{H1. The intensiveness (H1a) and the extensiveness (H1b) of the experience have a} positive effect on the experience value (attainment, learning, escapism, and fantasy).

\subsection{The dark side of the experience: satiety}

Kim (2014) states that tourists might experience negative feelings of anger and frustration during the course of a tourist activity resulting from unforeseen negative events (accidents, illness) or because of the nature of the destination or amenity. In our study, we consider that one such negative aspect is satiety, in other words, the weariness brought on by over-satisfying the desire for something.

Consumer satiety has been recognised in the marketing literature (Galak et al., 2009). Park and Jang (2014:21) define it as an affective consumer response after repeated 
exposure to a stimulus. In a similar vein, Poor et al. (2012) note that satiety curtails the pleasure or enjoyment felt arising from continued or repeated exposure to an experience. Individuals consume products and experiences up to the point at which they no longer enjoy them. This concept of satiety is supported by the optimal stimulation level theory (Steenkamp and Baumgartner, 1992). According to this theory, individual behaviour is influenced by the intrinsically motivated desire to accomplish a specific level of stimulation. The theory maintains that the relationship between the stimulus which individuals receive and their emotional reaction forms an inverted U-shaped function with the most successful intermediate levels of stimulation (Steenkamp and Baumgartner, 1992). When the level of stimulation is too low, individuals will attempt to increase stimulation. Yet, excess stimulation can trigger satiety and may lead to exploratory behaviour and variety seeking. Therefore, satiety might be induced as more and more of a given product is consumed, like a kind of internal meter which restricts the maximum level of stimulus a consumer can tolerate (McAlister, 1982). What is more, satiety not only comes about as a result of the amount consumed (Galak et al., 2013) but may also occur at a given moment merely because of the memory of past experiences (Galak et al., 2009).

What mainly triggers satiety is the frequency with which the consumer is exposed to a stimulus over a given period to time (Redden, 2008; Galak et al. 2009; 2013). Based on this idea, Park and Jang (2014) point to two factors that might further and hasten the process: (1) how often exposure occurs, and (2) the period of consumption. In the case of tourism, the accumulation of the activity and investment in a destination might lead to positive feelings and experiences up to when the marginal increase in said experiences given the additional investment in the destination proves minimal. Consuming more products or activities in the same place might cause visitor satiety 
when the latter feel they have exhausted all the possibilities the destination has to offer (Antón et al. 2014). Repeated consumption of experiences might make the destination seem familiar such that the learning element, which tends to appear in the early stages of consumption, disappears (Berlyne, 1970), and gives way to negative sensations. In sum, the intensiveness of the experience (the accumulation of time spent at a destination and the financial outlay) might create a tourist who is saturated.

Nevertheless, the same effect of the extensiveness of the experience is not to be expected. Studies into consumer satiety have highlighted a range of factors that moderate or delay the feeling of satiety such as increasing the perception of variety, focusing people's attention on differentiating aspects, or making the consumption less repetitive by means of the categorization or sub-categorization of the products consumed. (Redden, 2008). The greater the variety of activities a tourist engages in the higher their saturation threshold. Performing a range of activities might mean they do not accumulate repeated experiences and that it is more difficult to grow weary of any of them. Therefore,

H2a. The intensiveness of the experience has a positive influence on the tourist's satiety.

H2b. The extensiveness of the experience has a negative influence on the tourist's satiety.

\subsection{From experience and satiety to future tourist intentions}

Once the visit has concluded, individuals make an overall appraisal thereof which will impact on their future intentions. In this regard, studies describing the experience as a result, analyse the experience as an antecedent or consequence of other aspects. These studies seek to ascertain not only which factors impact on the experience (e.g. Verhoef et al., 2009) but also what role they play in consequences such as loyalty, satisfaction or 
word-of-mouth. Individuals' overall appraisal of their experience plays a key role in their future decisions and behaviour.

In the area of tourism, numerous studies support the relationship between experience value, satisfaction, and behaviour or future intentions (Chen and Chen, 2010; 2013; Hosany and Witham, 2009, 2010; Oh et al., 2007; Prebensen et al., 2014; Williams and Soutar, 2009; among others). Said future behaviour has often been measured as the intention to revisit the destination and to recommend the visit to others (Baker and Crompton, 2000; Opperman, 2000). Both kinds of intention are deemed indicators of visitor loyalty (Barroso et al, 2007). Nevertheless, today the intention to revisit a destination as an indicator of tourists' behaviour has lost ground to the recommendation factor. Due to the expansion of social networks and travel websites tourists can share their experiences and recommend a destination to thousands of people. In addition to these two dimensions, in the present study we have opted to include the intensification of the visit as a third dimension so as to broaden the measure of intention of individuals' future behaviour. After all, as De Rojas and Camarero (2008) have shown, the outcome of an experience is not confined to loyalty and to its attitudinal or behavioural components. Other consequences of experiences, such as intensification, might also prove interesting in the sense that they reflect the interest and motivation which individuals maintain after the visit, and might be expressed, for instance, by searching for information on the destination visited and on experience they have had. Although research focusing specifically on the tourist experience and on measuring this construct is more recent, previous studies have shown that the appraisal which individuals make of their consumption experience is linked to their future intention to return. As pointed out by McIntosh and Siggs (2005), tourist experiences are unique to a large degree, and contain a significant emotional charge and a high personal value. 
When tourists have a pleasant and enriching stay, they are more likely to want to repeat the experience and are therefore more likely to want to revisit the destination (Barroso et al., 2007; Chen and Tsai, 2007). In other words, the experience itself is the actual motivation and stimulus driving their purchase decision (Schmitt, 1999). Furthermore, the information gathered and processed during the tourist's stay and stemming from their own experience and personal knowledge might emerge, at least from their own particular perspective, as a more realistic and comprehensive source of information than can be obtained from secondary sources, since it is the result of their direct involvement and relation with the place (Beerli and Martín, 2004; Pearce, 1982; Phelps, 1986). This acquired knowledge allows visitors to appraise and judge the destination, based on which they will tend to share the experience with those around them and recommend it to a greater or lesser extent. Tourists like to talk about what they have learnt and felt during their visit (Carballo et al. 2015) and to evoke pleasant memories of their stay (Ali et al, 2016). A pleasant experience may therefore play a decisive role in their intention to share and recommend the trip to those around them (Chen and Tsai, 2007; Um et al. 2006).

Finally, the tourist experience is a cumulative process which provides individuals with emotional, cognitive and sensorial values. This cumulative process includes the planning stage of the trip, the actual visit itself and the subsequent appraisal (Carballo, Moreno, León and Brent Ritchie, 2015). When tourists undergo significant experiences, they engage more than anticipated (Harrison, 2001) and seek to intensify the visit with subsequent activities such as searching for further information about the destination or the type of experience they have had. 
H3. The experience value (attainment, learning, escapism, and fantasy) has a positive influence on the intention to return to the destination (H3a), the recommendation (H3b) and the intensification of the experience $(\mathrm{H3c})$.

In contrast, frequent repetitions of the visit which fail to provide value and to add anything new might lead to satiety with the destination. Should this occur, visitors will view the option to continue consuming the same type of product and amenity, and in the same place, as a negative experience, thus curtailing their intention to repeat the visit. Satiety leads to a reduction in marginal utility, making the consumer derive less utility as consumption of the product increases. In the field of tourism, if individuals feel saturated they will prefer not to continue consuming any more of the productdestination as a result of having reached the maximum possible level of stimulus (McAlister, 1982). The idea that repeated exposure to the same stimulus (destination) brings about less satisfaction than might be derived from a different stimulus (new destinations) could spark rejection behaviour towards the destination (Park and Jang, 2014). Satiety brings on a feeling of weariness and even displeasure, which might lead to the tourist not only refusing to consume more (to repeat the experience at the destination or to search for further information) but might also restrict their intention to recommend an experience they do not have fond memories of. Based on this, we posit: H4. Satiety has a negative influence on the intention to return to the destination $(\mathrm{H} 4 \mathrm{a})$, on recommendation $(\mathrm{H} 4 \mathrm{~b})$ and on the intensification of the experience $(\mathrm{H} 4 \mathrm{c})$.

The set of proposed hypotheses are summed up in Figure 1. 


\section{EMPIRICAL ANALYSIS}

\subsection{Sample selection and data collection}

To test the hypotheses, a survey was carried out amongst visitors to Segovia during the summer of 2014. Segovia is a historic city located in central Spain and declared World Heritage Site by UNESCO in 1985. It is a leading tourist destination in Spain for culture and cuisine. The city boasts great cultural uniqueness (thanks to its world famous Roman aqueduct and its cathedral), as well as a rich and long history and beautiful landscapes that make Segovia a destination which offers a wide range of possibilities for enjoyment. The small size of the city affords tourists many options for relaxing and enjoying the natural beauty of walking through green areas while visiting the city's iconic monuments such as the Alcazar (fortified palace), the Royal Mint or the Monastery of Parral.

Information was gathered in conjunction with the city's Tourism Watchdog. The study's population was defined as visitors over the age of 18 , and information was collected through a personal interview conducted on a sample of tourists. The team of interviewers were given precise instructions concerning the type of visitor to be selected. A system of quotas by tourist age and origin (domestic or foreign) was established. The sample was delimited in close collaboration with the Segovia City Council and Tourist Board (Segovia's official body for promoting tourism) whose monetary contribution proved decisive in supporting the financial cost of the research. Quotas were set based on the profile of tourists provided by relevant sources of tourism statistics: Spanish Statistics Institute (INE) and Segovia's Tourism Watchdog. Segovia is a place usually visited by foreign and national tourists because, as noted, it has an important international projection due to its declaration as a World Heritage Site, its being located in the centre of the country and its excellent communications links to the 
capital, Madrid. Based on these considerations, the final sample comprised an equal number of domestic and foreign visitors. In addition, only visitors who had been in the city for more than half of their planned stay (preferably who were about to conclude their stay) were chosen. The questionnaire was translated into English for foreign tourists. Interviewees were approached in different areas of the city frequented by tourists (the main sightseeing areas, near restaurants and hotels), on various days of the week and at different times of day. Visitors were selected by the interviewers according to these criteria (time expend and quotas by origin and age), and informed of the objectives of the research as well as the importance of their collaboration, whilst giving them complete freedom to answer the survey and thanking them for their cooperation. Finally, a total of 400 valid questionnaires were collected. In terms of ages, $28.6 \%$ of respondents were between 18 and 24 years old, $35.3 \%$ between 25 and 44 years old, $28.8 \%$ between 45 and 64 and $7.3 \%$ over 65 years of age.

\subsection{Measurement of the variables}

In order to measure the intensiveness of the experience we considered two indicators: the duration of the stay in terms of the number of days and the per capita spending per day in Euros (Petrick, 2004). The extensiveness of the visit was measured as the number of different activities performed, selected from among the various alternatives offered by this destination. This choice was based on the information obtained from the Head of the Visitor Reception Centre and two focus groups with tourists who reported and gave information about their experiences and the best things to do when in the city. This information allowed a preliminary list to be drawn up that was then complemented with activities (i.e. a tour by bicycle, a hot air balloon ride or a helicopter tour) available at the Segovia tourism website and tourist offices. Finally, in order not to prolong the 
interview, the activities that were most relevant and sought after by visitors were selected. The final list consisted of thirteen activities that included things visitors normally do in most places that are visited (i. e. taking photos, strolling through the city, etc.) as well as others more specifically related to the type of destination and its tourist offer (i.e. enjoying local cuisine, visiting monuments or taking an aerial tour of the city by helicopter).

The measurement scales for the dimensions of experience value (attainment, learning, escapism, and fantasy) and individual satiety, were created ad hoc for the study based on experience economy literature. All these measurement items were operationalized using 5-point Likert scales (from completely disagree to completely agree). Specifically, enrichment or learning and escapism and fantasy were measured using three indicators adapted from Oh, et al (2007), Hosany and Witham (2010) and Wu and Holsapple, (2014). To measure attainment and satiety, new scales based on a review of the literature as well as contributions by Hosany and Martin, 2011, Laing et al. 2014 and Verhoef et al. 2009, were constructed. The three dimensions of future behaviour intention considered were measured using a total of seven indicators, one for return intention, four for the intention to recommend (Barroso et al. 2007; Chen and Tsai, 2007; Lee et al., 2005; Oppermann, 2000) and a further two for intensification (De Rojas and Camarero, 2008). The questionnaire, especially ad hoc scales, was reviewed by the experts of Segovia's Tourism Watchdog and by two experts in tourism. They did not find any problem with the final wording of the indicators, and did not considered necessary to include additional items to clarify the content.

Table 1 shows the variables used in the study and their measurement indicators together with the corresponding descriptive statistics (mean and standard deviation). Since the sample consisted of 200 Spanish tourists and 200 foreign tourists, we tested the 
invariance of the measurement model to ensure cross-cultural validity by means of multigroup analysis, although we failed to find any significant differences in the loadings. Metric invariance between the groups can thus be accepted.

To avoid common method variance bias, we followed some recommendations of Podsakoff et al. (2003) when designing the questionnaire: item wording was revised so as to avoid ambiguous or unfamiliar terms; the question order did not match the causal sequence in the model. Harman's single-factor test was also conducted. Exploratory factor analysis with all the indicators reveals eight factors with an eigenvalue greater than one accounting for less than $76.7 \%$ of explained variance, and with a first factor explaining $17.17 \%$ of total variance, indicating that CMV is not an issue in our study.

\section{Insert here Table 1}

\subsection{Analysis and results}

Empirical testing of the proposed hypotheses was carried out by estimating a structural equation model using partial least squares structural equation modelling (PLS-SEM) with SmartPLS v3.0 (Ringle et al., 2015). This method is suitable when the goal is to predict key target constructs or identify key driver constructs (Hair et al., 2017). Moreover, it is a nonparametric method, without distributional assumptions. Since we have several items that do not follow normality criteria (problems of skewness and kurtosis), we considered this method to be appropriate. Information is provided concerning the outcomes of the validity analysis and the reliability of the measurement scales employed in the Table 2. Since all of the scales with multiple indicators are reflective, we offer the Cronbach alpha values $(\alpha)$, composite reliability $(\rho)$, variance extracted (AVE) and factorial loadings ( $\lambda$ values). All of them achieve acceptable 
values, above the recommended thresholds $(\alpha>0.7 ; \rho>0.7, \mathrm{AVE}>0.6$, and the standardized loadings $>0.7$ ), except for one item of satiety.

Despite normality problems, in order to confirm the reliability and validity of the scales, the measurement model fit was also tested by confirmatory factor analysis using AMOS software. All the measurement items significantly loaded on their corresponding constructs with loadings above 0.5 . Goodness of fit was also acceptable $\left(\chi^{2}(181)=\right.$ $471.61(\mathrm{p}=.000) ; \mathrm{GFI}=0.904 ; \mathrm{AGFI}=0.865 ; \mathrm{NFI}=0.931 ; \mathrm{CFI}=0.956 ; \mathrm{RMSEA}=0.063)$, thus confirming convergent validity. Table 2 shows the correlation matrix and the Fornell-Larcker criterion which ensures discriminant validity amongst the proposed variables. In addition, we confirmed that the heterotrait-monotrait ratio of correlations (HTMT criterion) is below 0.9 for all the reflective constructs (Henseler et al., 2015). Therefore, we can conclude that the reflective constructs evidence sufficient discriminant validity.

\section{Insert here Table 2 \\ Insert Table 3 here}

The results of the model estimated are shown in the Table 3 (full-mediation modelPLS). As a control variable, we included the effect of tourists' origin (Spanish versus foreign) on the endogenous variables, although we failed to find any significant effects. As regards hypothesis $\mathrm{H} 1$, findings show that the effect of the intensiveness of the experience in terms of expenditure has no significant effect on the experience value, except for the perception of fantasy (a negative effect). Furthermore, contrary to our expectations, the intensiveness of the experience in terms of time does have a negative effect on the perception of attainment and learning, yet shows no effect on escapism and fantasy. Therefore, we reject hypothesis H1a. Hypothesis H1b is, however, supported. 
The effect of the extensiveness of the experience on the experience value is positive and significant in the four elements considered (attainment, learning, escapism and fantasy). With regard to the effect of the activity on the tourist's satiety, H2a is partially supported. The longer the time spent in a destination, the greater the tourist's satiety, although the effect of expenditure is not significant. Likewise, the effect of the extensiveness of the experience on satiety proves significant. Thus, H2b is supported. Findings support the effect of the experience value on future tourist behaviour, although not all the dimensions of the experience value have the same effect. The experiences which have a positive and significant impact on the intention to return to the same destination in the future are attainment, escapism and fantasy (H3a is supported). As regards the intention to recommend the destination, it is the dimensions of attainment and learning that show a positive and significant effect, which is greater in the case of the former (H3b is supported). Finally, the intensification of the visit is determined by fantasy and attainment ( $\mathrm{H} 3 \mathrm{c}$ is supported).

The results obtained would seem to indicate that satiety has a negative and significant effect on the intention to repeat the destination ( $\mathrm{H} 4 \mathrm{a}$ is supported) and the intention to recommend ( $\mathrm{H} 4 \mathrm{~b}$ is supported), but has no significant impact on intensification $(\mathrm{H} 4 \mathrm{c}$ is rejected).

Our hypotheses suggest the existence of a full mediating effect of experience value and satiety in the relationship between the objective dimension of the experience (intensiveness and extensiveness) and behavioural intentions (intention to return, recommendation, and intensification). In order to verify whether the full-mediation model is better than other alternative models, it was compared to the partial-mediation model and with the no-mediation model. In order to compare the three models, we tested them using covariance-based structural equation modelling (CB-SEM), which is 
more suited to comparing alternative models. The estimation of the three models (Table 3) shows that neither the partial-mediation model (the comparison of the chi-square is not significant: $\left.\chi^{2}(9)=10.16, \mathrm{p}=.338\right)$ nor the no-mediation model (the comparison of the chi-square is not significant: $\left.\chi^{2}(13)=5.74, \mathrm{p}=.955\right)$ improve the goodness-of-fit. In both cases, the decrease in the chi-square statistic is not significant and the AGFI and RMSEA values are clearly worse in the partial-mediation and no-mediation models. In the no-mediation model, we observe a negative direct effect of time intensiveness on the intention to return, recommendation and intensification, while the effect of extensiveness is positive in the three cases. However, in the partial-mediation model, when we introduce the mediating effects, we observe that the direct effects of intensiveness and extensiveness on the behaviours after the visit are not significant. These results point to the mediating effect of experience and satiation. We examined the mediating role of the experience value and satiety through the indirect effects shown in Table 4.

\section{Insert Table 4 here}

As can be seen, the global effect of extensiveness is positive, whereas intensiveness in time exerts a negative effect. Intensiveness with regard to spending has no significant indirect effects on behaviour. According to our hypotheses, the global effect of intensiveness on behaviours is expected to be an inverted U-effect (a positive effect through experience and a negative effect when satiety appears). However, in line with the previous results, we failed to find any such effect. In fact, contrary to our expectations, the effect of intensiveness (time and expenditure) on the experience value is either negative or non-significant. In order to gain deeper insights into these effects, we also tested for the existence of inverted U-effects. We estimated curvilinear relationships for each pair of variables, and indeed found some significant quadratic 
effects (Table 5). Significant effects are represented in Figure 2. Even if the $\mathrm{R}^{2}$ values are low, we observe that attainment and learning are maximum for medium levels of expenditure, but when there is excessive spending the perception of a full and enriching experience decreases. Similarly, the perception of learning is greater when the time spent in the destination is brief, and decreases for long stays. Finally, the relationship between spending and fantasy seems to be adapted to a U-effect. This effect may be interpreted as a tourist's willingness to spend more during the visit when they are enthralled by it.

Insert Table 5 here

Insert Figure 2 here

\section{DISCUSSION}

\subsection{Findings and theoretical implications}

The present work provides deeper insights into current understanding of the effect of tourists' experience on their behaviour. Despite the progress made, certain areas of the iceberg of experience remain underexplored. A comprehensive grasp of consumption experience involves recognising individuals as doers, feelers and thinkers (Addison and Holbrook, 2001) and determining how these aspects of their behaviour shape their decisions.

Firstly, the work draws a distinction between an objective component of experience (activity intensiveness and extensiveness) and a subjective component (the value of experience). Secondly, we include the dark side of visitor experience; satiety. The aim is to ascertain to what extent visit intensiveness and extensiveness affect the value of tourist experience at the destination concerned. Further, we seek to find an answer to the question of whether the tourist visit, which is primarily conceived for pleasure, always 
generates experiences that are valued positively or whether, on the other hand, as occurs in other areas of consumption, there is a dark side where an extremely intense visit may lead to certain visitor weariness and saturation.

The intensiveness of the experience, specifically a long stay at the destination, leads to a negative opinion of the experience: tourist satiety. The greater the time spent in a destination, the greater the feeling of "too much", "too long" and a lack of interest. What is more, contrary to expectations, the findings highlight that an intense experience in terms of the time invested might have a negative impact on the experiential value perceived by the tourist. The greater the number of days devoted, the less the impression of having made the most of the visit and of the opportunities the destination has to offer, and even the feeling of learning and personal enrichment. There is even some evidence of a possible inverted U-effect of expenditure on experiences. One possible interpretation of these results is that when tourists spend more time and money at the destination, the remaining opportunities to do and learn new things diminish. Extra money and extra time spent at a destination will be used up on activities that do not provide any outcomes in terms of additional learning or doing interesting things. Consequently, whatever the learning and attainment process might have been up until a given moment, the perception of an enriching and instructive experience begins to fade, and the perception of "I have not made the most of my time" emerges.

Nevertheless, the findings do confirm the notion that when the tourist experience is richer in terms of activities, positive feelings are enhanced. Tourists who involve themselves fully with the destination, engaging in a greater array of activities, will value their experience more positively in all aspects: attainment, learning, fantasy and escapism. It can also be seen that the extensiveness of the experience diminishes the feeling of tourist satiety. These results are in line with those of Wang et al. (2013), who 
point out that being concerned about the possibility of becoming saturated increases consumer preference for the variety bundle. In the tourist context, this idea may summarize the increase in the tourists' tendency to perform a wider range of activities to avoid or reduce the satiation with their overall experience at the destination.

The tourist's behaviour (intention to return, recommendation, and intensification) is clearly determined by the subjective experience; in short, the feelings of attainment, learning, escapism, and fantasy.

As regards the intention to return, the influence of positive experiences on revisit intention has been confirmed by previous authors (Barnes et al., 2014; 2016). Our findings explore in greater depth those dimensions of the experience that contribute to said intention. Specifically, the greater the tourist's feeling that their investment in the visit has been rewarded and that the chosen destination fires their imagination and allows forgetting everything else, the greater their intention to return. Similar results are found for intensification. Making the most of a destination and the visit's capacity to let the tourist's imagination run wild and stir their fantasy are determinants of the tourist's individual and personal interest in the destination or type of tourist experience. When it comes to recommending the visit to others, particularly relevant are experiences that are more extrinsic and functional in nature and, as a result, easier to convey, and which offer a greater potential to persuade, namely attainment and enrichment. Escapism and fantasy, which are more intrinsic, hedonic and subjective, prove more difficult to convey and lend themselves less to being used as reasons to convince others to undertake the visit. Similarly, Hosany and Witham (2010) find that escapism does not affect the intention to recommend, although entertainment does. Of the four elements of the experience value, it is attainment, in other words the tourist's perception of an all-embracing experience, which has the greatest influence on 
their intentions since it impacts on the intention to return, to recommend the visit and on intensification.

In this regard, prominent is the effect exerted by escapism and fantasy on those intentions which concern only the individual and which may be performed personally; namely, the intention to repeat the destination and the intensification of the visit. Xu et al. (2017) have also emphasized the feeling of becoming immersed and of imaginative immersion (imagination, fantasy and empathy) as a relevant part of the experience. They suggest intensifying the onsite experience through game design elements: an augmented environment, imaginative stories, challenges brought on by game tasks/missions, etc. In this sense, our findings also show that the level of fantasy is higher for those tourists who have expended less in a destination (maybe they replace with fantasy what they have not acquired with money). However, when the level of expenditure is high, spending more money at a destination increases the feeling of fantasy.

In line with our proposal, we find different degrees of a negative feeling or sensation generated in the tourist during the visit; satiety or saturation. This feeling of weariness diminishes visitor intention to recommend the experience to others and undermines the intention to return to the same destination.

Finally, we find that experience value and satiety act as mediators between visit intensiveness (time) and extensiveness and future behaviour. Specifically, when the visit is long, both the perception of not making the most of it and of not learning enough as well as the sensation of satiety finally lessen the intention to repeat and to recommend the destination to others. Spending too long at the destination makes intensification diminish if visitors feel they have not fully capitalised on the visit. By contrast, more varied and diverse activities will boost the intention to return to the 
destination, recommend it and intensify the visit in that it increases the experience value, particularly if it heightens the feeling of having taken advantage of the visit. Our results expand previous findings of tourism literature examining the effect of varietyseeking. It has been shown that a variety-seeking tendency maintains the intention to recommend whilst reducing the intention to revisit (Barroso et al., 2007), although it does have a positive effect on medium-term revisit intention (Jang and Feng, 2007). Our findings show that when tourists are engaged in a varied activity they can maintain the intention to revisit.

\subsection{Managerial implications}

This study offers managers of tourist destinations some opportunities to improve the tourist experience and to foster positive future behaviour.

First, when designing their portfolio of products and experiences, tourist managers and firms should strive to strike the right balance between the amount invested (time and money) and variety in the activity undertaken. The tourist's stay should not be prolonged unnecessarily. Although one of the quantitative goals which tourist destinations often seek is to prolong the visit, our findings indicate that devoting too much time or money to a single destination leads to tourists not perceiving efficiency and attainment in their activity and might even bring on a feeling of satiety. In contrast, action must be taken to boost the variety of tourist activities at a given destination since this is undoubtedly an element which can generate a positive appraisal of the experience. Furthermore, it does not seem to spark any downside in terms of possible tourist saturation or satiety, but quite the opposite. Given that there are tourists who display varying degrees of saturation, enhancing the overall experience and, particularly, exploiting the visit through variety will reduce the feeling of satiety and 
increase the intention to return and recommend as well as boost the tourist's interest in the destination. Nevertheless, variety needs to be authentic and embedded in the destination (Lu et al., 2015) otherwise it will not produce the same benefits as the current variety offered, the experience will not be coherent and, eventually, this kind of variety will not be sustainable.

Second, it is important to offer the tourist options to shape their own behaviour and to achieve their objective of securing a satisfactory overall experience. By changing their activities or by consuming other products, consumers prevent the weariness and boredom that might otherwise be brought on by repeated consumption at the same place (Park and Jang, 2014; Poor et al. 2012). In this way, they continue to consume the same destination but differently. Having had a guided tour of the city, they might opt for a culinary experience which might encourage them to try out typical dishes or to devote their time to visiting museums or to sightseeing. Even though they are consuming more stimuli from the same destination, because these are different, the experience will feel like it is new. In this way, greater spending and more intense activity (visit intensity) will not necessarily translate to visitor satiety.

Third, depending on the objectives the destination seeks to offer, marketing managers should enhance those that have a greater influence on the behaviour they wish to stimulate. If the aim is to encourage repetition of the destination, planners should create experiences which provide value so as to boost the sensation of attainment and which at the same time stir visitor fantasy. If, on the other hand, the aim is to foster positive word-of-mouth they should seek to enhance the more objective aspects of the experience (attainment and enrichment), linked to the dimensions which reflect more the "what"; in other words, the things the client perceives, as opposed to the "how" (Um et al. 2006). 
In a similar line of reasoning, any improvement or extension of the supply should focus on creating experiences which further the feeling of attainment in the visitor, since this is the dimension that has a wider positive impact (intention to return-recommendintensify). New experiences that respond to visitor interests and which have the right timing and enable them to get to know the various attractions the destination has to offer can help to accomplish this.

\subsection{Limitations and future research}

Some limitations can be found in this study. First, it focuses on a specific destination. Although allowing us to measure the intensiveness and extensiveness of the experience in relation to a given destination (otherwise, the time, expenditure and activities of the tourists would not be comparable), it might condition the kind of unique experiences offered by the destination.

Second, tourist profile has not been taken into account, nor has their prior experience as tourists, or their interest in the destination. Tourist involvement in the destination might increase their saturation threshold and enhance their capacity to enjoy a destination more. In this line, the optimal stimulation level theory (Steenkamp and Baumgartner, 1992) contends that there are stable individual differences in the perceived ideal level of stimulation. Tourists might need different levels of stimulation if their interest in the destination is to be maintained and if satiety is to be avoided. Future research should thus consider tourists' prior experience, involvement, age, or culture as well as other aspects which may moderate the impact of the activity on satiety. Cross-cultural analysis might provide insights into differences in tourists' saturation threshold. Likewise, the country of origin might also moderate the effect of the experience on future behaviours. 
Third, regarding the measurement of the variables, the intensity and variety of the activities undertaken, such as the number of days and activities, have been measured specifically. These measures might be complemented by adding others such as visitor perception of the extent to which the visit has proved intense or varied. In addition, intensity has been measured in time and money. Future studies should also contemplate other indicators of intensity such as the number of times certain activities have been repeated (how many times have they visited the same monuments or museums? How many times have they eaten at the same restaurant?). Finally, the intention to return may not be a relevant measure of the outcomes of tourist experiences, particularly when they are motivated by novelty seeking. Tourism studies should use new metrics that reflect the main return on tourists' experiences such as recommendation and content generation in social networks and travel websites.

\section{REFERENCES}

Addis, M. and Holbrook, M.B. (2001). "On the Conceptual Link between Mass Customisation and Experiential Consumption. An Explosion of Subjectivity”. Journal of Consumer Behaviour 1 (1): 50-66.

Ali, F., Hussain, K. and Ragavan, N. A. (2014). "Memorable customer experience. examining the effects of customers experience on memories and loyalty in Malaysian resort hotels". Procedia-Social and Behavioral Sciences 144: 273- 279.

Anderson, T.D. (2007). "The tourist in the experience economy". Scandinavian Journal of Hospitality and Tourism 7 (1): 46-58.

Antón, C., Camarero, C. and Laguna, M. (2017). "Toward a new approach of destination loyalty drivers. Satisfaction, visit intensity and motivation”. Current Issues in Tourism, $20(3)$, 
Ariely, D. (1998). "Combining experiences over the time. The effect of Duration, Intensity Changes and On Line Measurement on Retrospective Pain Evaluation”. Journal of Behavioral Decision Making 11: 19-45

Arnauld, E.J., and Price, L.L. (1993). "River Magic. Extraordinary experience and the extended service encounter”. Journal of Consumer Research 20 (1): 24-45.

Baker, D.A., and Crompton, J.L. (2000). "Quality, satisfaction and behavioral intentions". Annals of Tourism Research 27 (3): 785-804.

Barnes, S., Mattsson, J. and Sørensen, F. (2014). "Destination brand experience and visitor behavior. Testing a scale in the tourism context". Annals of Tourism Research 48: 121-139.

Barnes, S.J., Mattsson, J., and Sørensen, F. (2016). "Remembered experiences and revisit intentions: A longitudinal study of safari park visitors”. Tourism Management 57 (December): 286-294

Barroso Castro, C., Martín Armario, E., and Martín Ruiz, D. (2007). "The influence of market heterogeneity on the relationship between a destination's image and tourists' future behavior". Tourism Management 28 (1): 175-187.

Beerli, A. y Martin, J.D. (2004). "Factor influencing destination image". Annals of Tourism Research 31 (3): 657-681.

Berlyne, D.E. (1970). "Novelty, complexity, and hedonic value". Perception and Psychophysics 8 (5): 279-286.

Bowsijk, A., Thijssen, T. and Peelen, E. (2007). The experience economy: A new perspective. Pearson Education Benelux, Amsterdam, The Netherlands.

Brakus J J, Schmitt B H and Zarantonello L. (2009). "Brand Experience. What Is It? How Is It Measured? Does It Affect Loyalty?” Journal of Marketing 73 (3): 52 - 68.

Carballo, R., Moreno, S., León, C. and Brent Ritchie, J.R. (2015). "La creación y promoción de experiencias en un destino turístico. Un análisis de la investigación y 
necesidades de actuación”. Cuadernos de Turismo 35: 71-94.

Carlson, R. (1997). Experienced Cognition. New York: Lawrence Erlbaum Association. Chen, C. and Tsai, D. (2007). "How destination image and evaluative factors affect behavioral intentions?" Tourism Management 28 (4): 1115-1122.

Chen, C.F. and Chen, F.S. (2010): "Experience quality, perceived value, satisfaction and behavioral intentions for heritage tourists". Tourism Management, 31 (1), 29-35.

Csikszentmihalyi, M. (2000). "The Cost and Benefits of Consuming". Journal of Consumer Research 27 (2): 267-272.

De Rojas, C. and Camarero, C. (2008). "Visitors' experience, mood and satisfaction in a heritage context. Evidence from an interpretation center". Tourism Management 29 (3): $525-537$.

Galak, J., Kruger, J. and Loewenstein, G. (2013). "Slow Down! Insensitivity to Rate of Consumption Leads to Avoidable Satiation". Journal of Consumer Research 39 (5): 993 1009.

Galak, J., Redden, J.P., and Kruger, J. (2009). "Variety amnesia. recalling past variety can accelerate recovery from satiation”. Journal of Consumer Research 36 (4): 575-584. Hair, J. F., Hult, G. T. M., Ringle, C. M., and Sarstedt, M. (2017). A Primer on Partial Least Squares Structural Equation Modeling. Thousand Oaks: Sage. Second edition. Harrison, S. (2001). “Thinking about tourism”. International Sociology 16: 152-172. Henseler, J., Ringle, C.M. and Sarstedt, M. (2015), "A new criterion for assessing discriminant validity in variance-based structural equation modeling", Journal of the Academy of Marketing Science, 43 (1): 115-135.

Hoeffler, S., Ariely, D., West, P., and Duclos, R. (2013). "Preference exploration and learning: The role of intensiveness and extensiveness of experience". Journal of Consumer Psychology 23 (3): 330-340. 
Holbrook, M. B. (1994). "The nature of customer value. An anthology of Services in the Consumption Experience". In R. Rust and R. L. Oliver (Eds.), Service Quality. New Directions in Theory and Practice (pp.21-71). Thousand Oaks: Sage Publications. Holbrook, M. B., and Hirschman, E. C. (1982). “The experiential aspects of consumption. Consumer fantasies, feelings, and fun". Journal of Consumer Research 9 (2): 132-140. Hosany, S. and Martin, D. (2011). "Self-image congruence in consumer behavior". Journal of Business Research 65 (5): 685-691.

Hosany, S. and Witham, M. (2010). "Dimensions of Cruisers' Experiences, Satisfaction and Intention to Recommend”. Journal of Travel Research 49 (3): 351-364.

Hosany, S., \& Witham, M. (2009). 'Dimensions of cruisers' experiences, satisfaction and intention to recommend". Journal of Travel Research, 49 (3), 351-364.

Jaakkola, E., Helkkula, A. and Aarikka-Stenroos (2015). "Service experience co-creation. conceptualization, implications, and future research directions". Journal of Service Management 26 (2): 182-205.

Jang, S. C., and Feng, R. (2007). "Temporal destination revisit intention: the effect of novelty seeking and satisfaction”. Tourism Management, 28 (2), 580-590.

Kim, J.H. (2014). "The antecedents of memorable tourism experiences. The development of a scale to measure the destination attributes associated with memorable experiences". Tourism Management 44: 34-45.

Kim, J.H., Ritchie, J.R.B. and McCormick, B. (2012). "Development of a scale to measure memorable tourism experiences”. Journal of Travel Research 51 (1): 12-25.

Laing, J. Wheeler, F. Reeves, K. and Frost, W. (2014). “Assessing the experiential value of heritage assets. A case study of a Chinese heritage, Bendigo, Australia”. Tourism Management 40: 180-182.

Lee, C., Lee, Y. and Lee, B. (2005). "Korea's Destination image formed by the 2002 
World Cup". Annals of Tourism Research 32 (4): 839-858.

Lee, J. and Beeler, C. (2009). "An investigation of predictors of satisfaction and future intention. Links to motivation, involvement and service quality in a local festival". Event Management 13 (1): 17-29.

Lewis, R., and Chambers, R. (2000). Marketing leadership in hospitality. Foundations and practices. New York: John Wiley and Sons.

Lu, L., Chi, C.G., and Liu, Y. (2015). "Authenticity, involvement and image. Evaluating tourist experiences at historic districts". Tourism Management 50: 85-96.

Mathwick, C., Malhotra, N. K., and Rigdon, E. (2001). "Experiential value, conceptualization, measurement and application in the catalog and Internet shopping environment". Journal of Retailing 77 (1): 39-56.

McAlister, L. (1982). “A dynamic attribute satiation model of variety-seeking behavior”. Journal of Consumer Research 9 (2): 141-150.

McIntosh, A., and Siggs, A. (2005). "An exploration of the Experiential Nature of Boutique Accomodation”. Journal of Travel Research 44 (1) 74-81.

McKercher, B., Denizci-Guillet, B. and Ng, E. (2012). "Rethinking Loyalty". Annals of Tourism Research 39 (2): 708-734.

Meyer, C. and Schwager, A. (2007). "Understanding customer experience”. Harvard Business Review 85 (2): 116-126.

Mook, C. Iverson, J. (2000). “Expenditure-based segmentation: Taiwanese tourist to Guam”. Tourism Management 21: 299-305.

Neuhofer, B.; Buhalis, D. and Ladkin, A. (2014). "A typology of technology-enhanced tourism experiences". International Journal of Tourism Research 16 (4): 340-350.

Oh, H., Fiore, A.M., and Jeong, M. (2007). "Measuring experience economy concepts. tourism applications". Journal of Travel Research 46 (2): 119-132. 
Oppermann, M. (2000). “Tourism destination loyalty”. Journal of Travel Research 39 (1): 78-84.

Otto J.E. and Ritchie, R.B. (1996). "The service experience in tourism". Tourism Management 17 (3): 165-174.

Park, J. Y., and Jang, S. C. S. (2014). "Revisit and Satiation Patterns. Are your restaurant customers satiated?" International Journal of Hospitality Management 38: 20-29.

Pearce, P. L., (1982). "Perceived Changes in Holiday Destination”. Annals of Tourism Research 9 (2): 145-164.

Petrick, J. F. (2004). “Are Loyal visitors the desired visitors?” Tourism Management 25: 463-470.

Phelps, A. (1986). "Holiday Destination Image-The Problem of Assessment. An Example Developed in Menorca”. Tourism Management 7 (3): 168-180.

Pine II, B. J. and Gilmore, J. H. (1999). The experience economy. Boston: Harvard Business School Press.

Pine II, B.J. and Gilmore, J.H. (1998). "Welcome to the experience economy". Harvard Business Review 76 (4): 97-105.

Poor, M. Duhachek, A. and Krishnan, S. (2012). "The moderating role of emotional differentiation on satiation". Journal of Consumer 22 (4): 507-519.

Preacher, K. J., and Hayes, A. F. (2008). "Asymptotic and resampling strategies for assessing and comparing indirect effects in multiple mediator models". Behavior Research Methods 40 (3): 879-891.

Prebensen, N.K. and Xie, J. (2017). "Efficacy of co-creation and mastering on perceived value and satisfaction in tourists' consumption". Tourism Management 60 (June): 166176.

Prebensen, N.K., Vitterson, J. and Dahl, T. (2013). "Value co-creation significance of 
tourist resources". Annals of Tourism Research 42 (July): 240-261.

Prebensen, N.K., Woo, E., Chen, J.S. and Uysal, M. (2012). "Motivation and Involvement as Antecedents of the Perceived Value of the Destination Experience". Journal of Travel Research 52 (2): 253-564.

Prebensen, N.P., Woo, W., and Uysal, M.S. (2014). Experience value: Antecedents and consequences. Current Issues in Tourism, 17(10), 910-928.

Redden, J.P. (2008). "Reducing satiation. The role of categorization level". Journal of Consumer Research 34 (5): 624-634.

Ringle, C. M., Wende, S., and Becker, J.M. (2015). SmartPLS 3. Bönningstedt. SmartPLS $\mathrm{GmbH}$.

Schmitt, B.H. (1999). Experiential Marketing, New York: Free Press Steenkamp, Jan-Benedict E.M. and Hans Baumgartner (1992), "The Role of Optimum Stimulation Level in Exploratory Consumer Behavior," J. Consumer Research 19(December): 434-48.

Um, S. Chon, K. and Ro, Y. (2006). “Antecedents of revisit intention”. Annals of Tourism Research 33 (4): 1141-1158.

Verhoef, P.C., Lemon, K.N., Parasuraman, A., Roggeveen, A., Tsiros, M. and Schlesinger, L.A. (2009). "Customer experience creation. Determinants, dynamics and management strategies". Journal of Retailing 85 (1): 31-41.

Walls, A.R. Okumus, F. Wang, Y. and Kwun, D.J. (2011). “An epistemological view of consumer experiences”. International Journal of Hospitality Management 30 (1): 10-21. Wang, X. Sun, L., and Keh, H.T. (2013). "Consumer responses to variety in product bundles. The moderating role of evaluation mode". International Journal of Research in Marketing 30 (4): 335-342.

Williams, P. and Soutar, G. N. (2009). "Value, satisfaction and behavioral intentions in 
an adventure tourism context”. Annals of Tourism Research, 36 (3), 413-438.

Wu, J. and Holsapple, C. (2014). "Imaginal and emotional experiences in pleasureoriented IT usage. A hedonic consumption perspective". Information and Management 51 (1): 80-92.

Xu, F., Buhalis, D., and Weber, J. (2017). "Serious games and the gamification of tourism”. Tourism Management, 60 (June): 244-256

Yoon, Y. and Uysal, M. (2005). “An examination of the effects of motivation and satisfaction on destination loyalty: A structural model". Tourism Management 26: 45-56. 
Figure 1. Proposed model

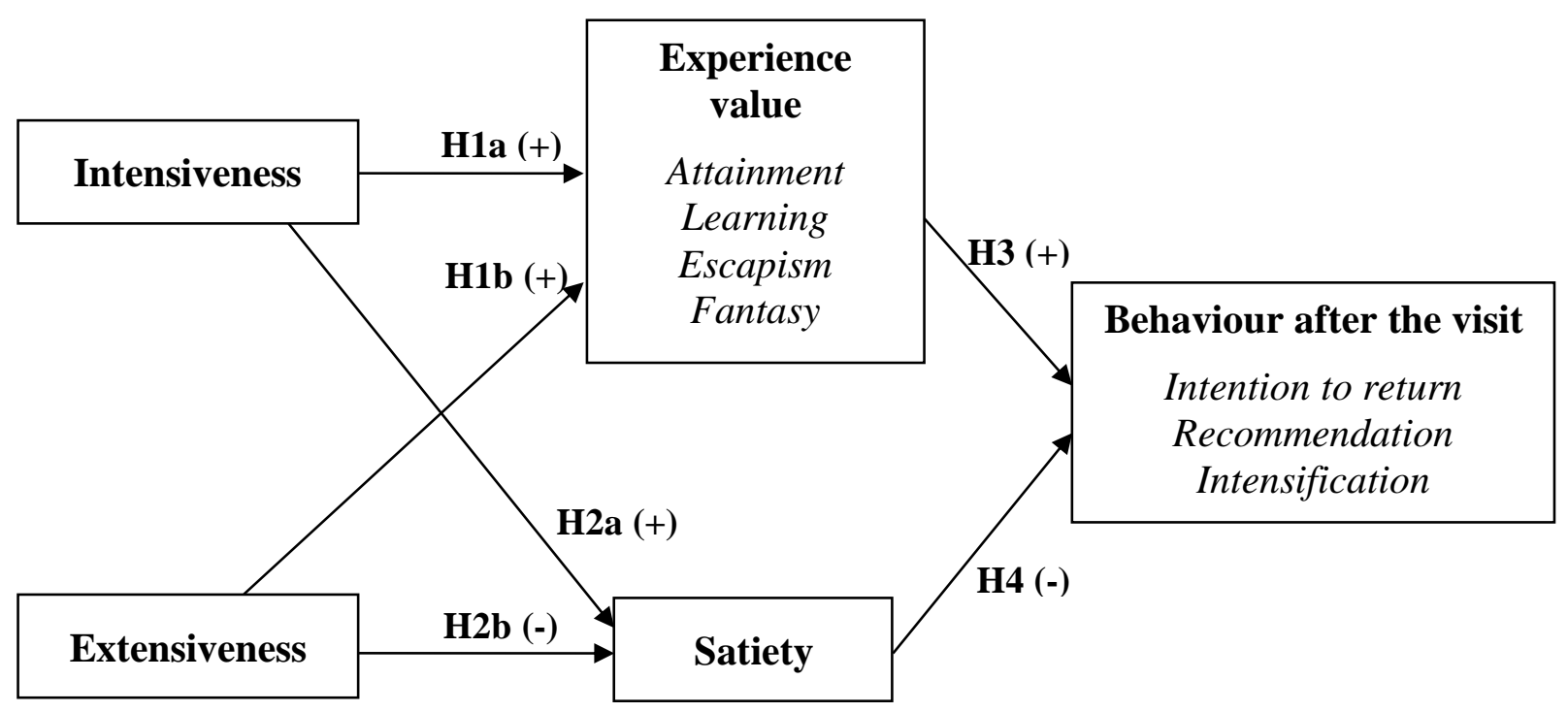


Figure 2. Quadratic effects
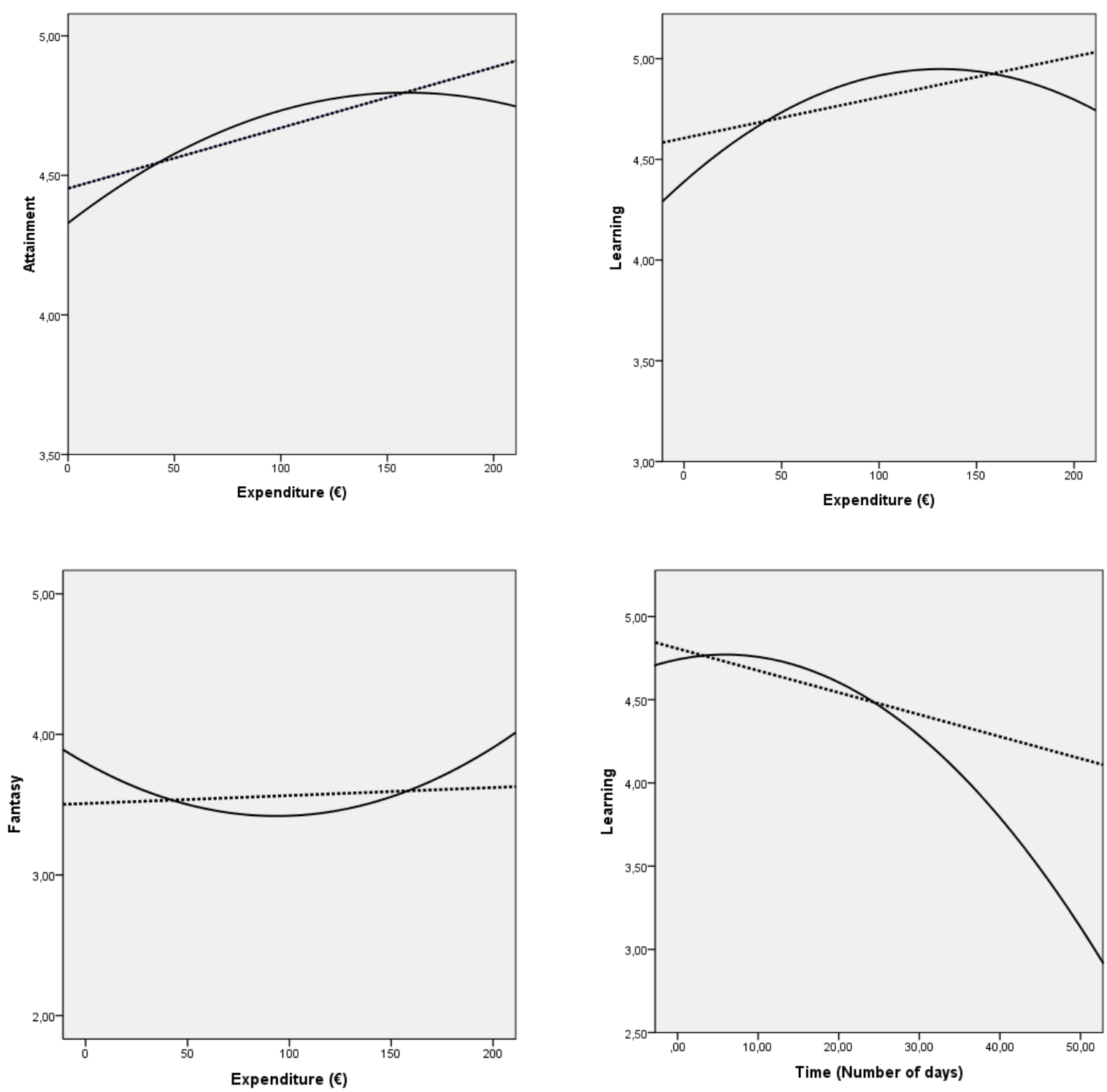
Table 1. Measurement of variables

\begin{tabular}{|c|c|c|c|c|}
\hline & Mean & S.D. & $\begin{array}{l}\text { Loadings } \\
\text { PLS }\end{array}$ & $\begin{array}{c}\text { Loadings } \\
\text { Amos }\end{array}$ \\
\hline \multicolumn{5}{|l|}{ Intensiveness (expenditure) } \\
\hline Spending per person and day in $€$ & 73.07 & 53.255 & & \\
\hline \multicolumn{5}{|l|}{ Intensiveness (time) } \\
\hline $\begin{array}{l}\text { Extensiveness (Number of activities performed) } \\
\text { Strolling around the city; Visiting monuments and/or museums; Following a } \\
\text { tourist route; Taking photographs; Eating in restaurants and enjoying the local } \\
\text { cuisine; Attending cultural events and/or activities (theatre, concert); Going to } \\
\text { information offices or points; Taking the sightseeing bus; Going on a guided } \\
\text { tour; Buying mementos or souvenirs, other purchases; Doing outdoor activities } \\
\text { (trips, camping, hiking, sport); Going out at night; Others }\end{array}$ & 7.07 & 1.881 & & \\
\hline \multicolumn{5}{|l|}{ Experience $^{\mathrm{a}}$} \\
\hline \multicolumn{5}{|l|}{ Attainment $(\alpha=0.806 ; \rho=0.886 ; A V E=0.722)$} \\
\hline I have made the most of my time during the visit & 4.58 & 0.663 & 0.764 & 0.635 \\
\hline I have seen and/or done many interesting things & 4.69 & 0.681 & 0.917 & 0.900 \\
\hline I have enjoyed a full experience at the destination & 4.54 & 0.858 & 0.861 & 0.784 \\
\hline \multicolumn{5}{|l|}{ Learning $(\alpha=0.947 ; \rho=0.966 ; A V E=0.904)$} \\
\hline The experience has been enriching & 4.78 & 0.561 & 0.951 & 0.916 \\
\hline The experience has been instructive & 4.74 & 0.603 & 0.974 & 0.991 \\
\hline During the visit, I have learnt things I didn't know & 4.72 & 0.692 & 0.927 & 0.875 \\
\hline \multicolumn{5}{|l|}{ Escapism $(\alpha=0.944 ; \rho=0.964 ; A V E=0.900)$} \\
\hline The visit has enabled me to get away from it all & 3.94 & 1.112 & 0.936 & 0.886 \\
\hline The visit has enabled me to leave my cares and pressure behind & 4.00 & 1.056 & 0.968 & 0.976 \\
\hline The visit has enabled me to forget everything else & 3.85 & 1.071 & 0.941 & 0.907 \\
\hline \multicolumn{5}{|l|}{ Fantasy $(\alpha=0.833 ; \rho=0.898 ; A V E=0.747)$} \\
\hline The visit has stirred my imagination & 3.47 & 1.296 & 0.868 & 0.827 \\
\hline During the visit I have built my own fantasies and hopes & 3.78 & 1.125 & 0.881 & 0.776 \\
\hline I have felt captivated by the visit & 3.38 & 1.248 & 0.843 & 0.774 \\
\hline \multicolumn{5}{|l|}{ Satiety $^{\text {a }}(\alpha=0.711 ; \rho=0.835 ; A V E=0.631)$} \\
\hline It has been too much of the same & 1.42 & 0.800 & 0.847 & 0.710 \\
\hline I have spent too long at the destination & 1.24 & 0.667 & 0.869 & 0.807 \\
\hline I think I have spent too much money on this trip & 1.63 & 0.933 & 0.647 & 0.513 \\
\hline \multicolumn{5}{|l|}{ Intention to return ${ }^{\mathrm{a}}$} \\
\hline I intend to visit Segovia again in the future & 4.72 & 0.735 & - & - \\
\hline \multicolumn{5}{|l|}{ Recommendation $^{\text {a }}(\alpha=0.944 ; \rho=0.967 ; A V E=0.879)$} \\
\hline I will recommend this tourist destination to friends and acquaintances & 4.89 & 0.443 & 0.923 & 0.847 \\
\hline When talking about this city I will say positive things & 4.92 & 0.408 & 0.950 & 0.970 \\
\hline When talking about my experience in this city I will say positive things & 4.91 & 0.404 & 0.957 & 0.958 \\
\hline I will recommend this type of experience for this or other destinations & 4.90 & 0.383 & 0.917 & 0.862 \\
\hline \multicolumn{5}{|l|}{ Intensification $^{\mathrm{a}}(\alpha=0.729 ; \rho=0.876 ; A V E=0.781)$} \\
\hline I intend to search for more information about Segovia & 4.03 & 1.294 & 0.830 & 0.966 \\
\hline I intend to search for more information about this experience & 4.43 & 1.131 & 0.932 & 0.592 \\
\hline
\end{tabular}

$\alpha$ : Cronbach's alpha; $\rho$ : Composite reliability

$\left({ }^{a}\right)$ Variables measured on Likert scales from 1 to 5. 
T Table 2. Correlation matrix, Fornell-Larcker criterion, and HTMT ratio

\begin{tabular}{|c|c|c|c|c|c|c|c|c|c|c|c|}
\hline & (1) & (2) & (3) & (4) & (5) & (6) & (7) & (8) & (9) & (10) & (11) \\
\hline (1) Escapism & 0.949 & 0.391 & 0.218 & 0.473 & 0.422 & 0.113 & 0.348 & 0.042 & 0.300 & 0.319 & 0.166 \\
\hline (2) Attainment & 0.346 & 0.850 & 0.231 & 0.196 & 0.443 & 0.178 & 0.386 & 0.180 & 0.605 & 0.646 & 0.519 \\
\hline (3) Extensiveness & 0.212 & 0.212 & n.a. & 0.252 & 0.175 & 0.416 & 0.123 & 0.146 & 0.331 & 0.119 & 0.124 \\
\hline (4) Fantasy & 0.423 & 0.169 & 0.226 & 0.864 & 0.468 & 0.054 & 0.280 & 0.042 & 0.242 & 0.221 & 0.056 \\
\hline (5) Intensification & 0.347 & 0.357 & 0.173 & 0.391 & 0.884 & 0.104 & 0.524 & 0.098 & 0.369 & 0.377 & 0.267 \\
\hline (6) Intensiveness (expenditure) & 0.109 & 0.155 & 0.414 & 0.025 & 0.094 & n.a. & 0.109 & 0.098 & 0.148 & 0.021 & 0.129 \\
\hline (7) Intention to return & 0.337 & 0.351 & 0.123 & 0.263 & 0.465 & 0.109 & n.a. & 0.120 & 0.318 & 0.510 & 0.296 \\
\hline (8) Intensiveness (time) & -0.041 & -0.163 & 0.145 & -0.022 & -0.076 & -0.097 & -0.119 & n.a. & 0.113 & 0.091 & 0.207 \\
\hline (9) Learning & 0.283 & 0.531 & 0.320 & 0.216 & 0.318 & 0.142 & 0.311 & -0.108 & 0.951 & 0.496 & 0.348 \\
\hline (10) Recommendation & 0.302 & 0.566 & 0.116 & 0.202 & 0.324 & 0.020 & 0.497 & -0.088 & 0.475 & 0.937 & 0.435 \\
\hline (11) Satiety & -0.100 & -0.422 & -0.095 & -0.018 & -0.209 & -0.123 & -0.256 & 0.177 & -0.302 & -0.373 & 0.794 \\
\hline
\end{tabular}

The diagonal shows the squared-root of the AVE. Over the diagonal is shown the Heterotrait-Monotrait ratio 
Table 3. Model estimation

\begin{tabular}{|c|c|c|c|c|c|c|c|c|c|c|}
\hline \multirow[b]{3}{*}{ Hypotheses } & & \multirow[b]{3}{*}{ Relationships } & & & \multicolumn{6}{|c|}{ Comparison of models (AMOS) } \\
\hline & & & \multicolumn{2}{|c|}{$\begin{array}{l}\text { Full-mediation } \\
\text { model }(P L S)\end{array}$} & \multicolumn{2}{|c|}{$\begin{array}{c}\text { Full } \\
\text { mediation } \\
\text { model }\end{array}$} & \multicolumn{2}{|c|}{$\begin{array}{c}\text { Partial } \\
\text { mediation } \\
\text { model }\end{array}$} & \multicolumn{2}{|c|}{$\begin{array}{c}\text { No mediation } \\
\text { model }\end{array}$} \\
\hline & & & $\beta^{a}$ & $p$ & $\beta$ & $p$ & $\beta$ & $p$ & $\boldsymbol{\beta}$ & $p$ \\
\hline \multirow{8}{*}{$\begin{array}{l}\text { Control } \\
\text { effects }\end{array}$} & & Country $^{\mathrm{b}} \rightarrow$ Attainment $^{2}$ & -0.020 & n.s. & -0.029 & n.s. & -0.029 & n.s. & & \\
\hline & & Country $\rightarrow$ Learning & -0.041 & n.s. & -0.034 & n.s. & -0.034 & n.s. & & \\
\hline & & Country $\rightarrow$ Escapism & -0.040 & n.s. & -0.027 & n.s. & -0.027 & n.s. & & \\
\hline & & Country $\rightarrow$ Fantasy & -0.007 & n.s. & -0.009 & n.s. & -0.009 & n.s. & & \\
\hline & & Country $\rightarrow$ Satiety & -0.009 & n.s. & -0.006 & n.s. & -0.006 & n.s. & & \\
\hline & & Country $\rightarrow$ Intention to return & -0.034 & n.s. & -0.037 & n.s. & -0.030 & n.s. & -0.026 & n.s. \\
\hline & & Country $\rightarrow$ Recommendation & 0.046 & n.s. & 0.038 & n.s. & 0.010 & n.s. & -0.008 & n.s. \\
\hline & & Country $\rightarrow$ Intensification & -0.060 & n.s. & -0.070 & n.s. & -0.065 & n.s. & -0.076 & n.s. \\
\hline \multirow{12}{*}{$\begin{array}{l}\text { H1. Effect } \\
\text { of activity } \\
\text { on } \\
\text { experience } \\
\quad \text { value }\end{array}$} & H1a & Intensiveness (expend) $\rightarrow$ Attainment & 0.039 & n.s. & -0.003 & n.s. & -0.003 & n.s. & & \\
\hline & & Intensiveness (expend) $\rightarrow$ Learning & -0.031 & n.s. & -0.029 & n.s. & -0.029 & n.s. & & \\
\hline & & Intensiveness (expend) $\rightarrow$ Escapism & 0.001 & n.s. & -0.007 & n.s. & -0.007 & n.s. & & \\
\hline & & Intensiveness (expend) $\rightarrow$ Fantasy & -0.099 & $*$ & -0.109 & $*$ & -0.109 & $*$ & & \\
\hline & & Intensiveness (time) $\rightarrow$ Attainment & -0.192 & $* * *$ & -0.229 & $* * *$ & -0.229 & $* * *$ & & \\
\hline & & Intensiveness (time) $\rightarrow$ Learning & -0.161 & $* *$ & -0.140 & $* *$ & -0.140 & $* *$ & & \\
\hline & & Intensiveness (time) $\rightarrow$ Escapism & -0.070 & n.s. & -0.084 & n.s. & -0.084 & n.s. & & \\
\hline & & Intensiveness (time) $\rightarrow$ Fantasy & -0.071 & n.s. & -0.076 & n.s. & -0.076 & n.s. & & \\
\hline & H1b & Extensiveness $\rightarrow$ Attainment & 0.219 & $* * *$ & 0.275 & $* * *$ & 0.275 & $* * *$ & & \\
\hline & & Extensiveness $\rightarrow$ Learning & 0.348 & $* * *$ & 0.324 & $* * *$ & 0.324 & $* * *$ & & \\
\hline & & Extensiveness $\rightarrow$ Escapism & 0.213 & $* * *$ & 0.241 & $* * *$ & 0.241 & $* * *$ & & \\
\hline & & Extensiveness $\rightarrow$ Fantasy & 0.275 & $* * *$ & 0.307 & $* * *$ & 0.307 & $* * *$ & & \\
\hline \multirow{3}{*}{$\begin{array}{l}\text { H2. Effect } \\
\text { of activity } \\
\text { on satiety }\end{array}$} & $\mathrm{H} 2 \mathrm{a}$ & Intensiveness (expend) $\rightarrow$ Satiety & -0.069 & n.s. & -0.055 & n.s. & -0.055 & n.s. & & \\
\hline & & Intensiveness (time) $\rightarrow$ Satiety & 0.186 & $* *$ & 0.230 & $* * *$ & 0.230 & $* * *$ & & \\
\hline & $\mathrm{H} 2 \mathrm{~b}$ & Extensiveness $\rightarrow$ Satiety & -0.095 & $*$ & -0.136 & $*$ & -0.136 & $*$ & & \\
\hline \multirow{12}{*}{$\begin{array}{l}\text { H3. Effect } \\
\text { of } \\
\text { experience } \\
\text { value on } \\
\text { behaviour }\end{array}$} & $\mathrm{H} 3 \mathrm{a}$ & Attainment $\rightarrow$ Intention to return & 0.146 & $*$ & 0.174 & $* *$ & 0.173 & $* *$ & & \\
\hline & & Learning $\rightarrow$ Intention to return & 0.107 & n.s. & 0.062 & n.s. & 0.072 & n.s. & & \\
\hline & & Escapism $\rightarrow$ Intention to return & 0.184 & $* *$ & 0.144 & $* *$ & 0.145 & $* *$ & & \\
\hline & & Fantasy $\rightarrow$ Intention to return & 0.135 & $* *$ & 0.166 & $* * *$ & 0.176 & $* * *$ & & \\
\hline & $\mathrm{H} 3 \mathrm{~b}$ & Attainment $\rightarrow$ Recommendation & 0.353 & $* * *$ & 0.440 & $* * *$ & 0.448 & $* * *$ & & \\
\hline & & Learning $\rightarrow$ Recommendation & 0.208 & $* * *$ & 0.136 & $* *$ & 0.147 & $* *$ & & \\
\hline & & Escapism $\rightarrow$ Recommendation & 0.083 & n.s. & 0.027 & n.s. & 0.033 & n.s. & & \\
\hline & & Fantasy $\rightarrow$ Recommendation & 0.061 & n.s. & 0.061 & n.s. & 0.067 & n.s. & & \\
\hline & $\mathrm{H} 3 \mathrm{c}$ & Attainment $\rightarrow$ Intensification & 0.173 & $*$ & 0.278 & $* * *$ & 0.280 & $* * *$ & & \\
\hline & & Learning $\rightarrow$ Intensification & 0.096 & n.s. & 0.051 & n.s. & 0.050 & n.s. & & \\
\hline & & Escapism $\rightarrow$ Intensification & 0.126 & n.s. & 0.012 & n.s. & 0.010 & n.s. & & \\
\hline & & Fantasy $\rightarrow$ Intensification & 0.286 & $* * *$ & 0.477 & $* * *$ & 0.478 & $* * *$ & & \\
\hline \multirow{3}{*}{$\begin{array}{l}\text { H4. Effect } \\
\text { of satiety on } \\
\text { behaviour }\end{array}$} & $\mathrm{H} 4 \mathrm{a}$ & Satiety $\rightarrow$ Intention to return & -0.140 & $*$ & -0.156 & $* *$ & -0.146 & $*$ & & \\
\hline & $\mathrm{H} 4 \mathrm{~b}$ & Satiety $\rightarrow$ Recommendation & -0.153 & $*$ & -0.169 & $* * *$ & -0.180 & $* * *$ & & \\
\hline & $\mathrm{H} 4 \mathrm{c}$ & Satiety $\rightarrow$ Intensification & -0.087 & n.s. & -0.116 & $*$ & -0.118 & $*$ & & \\
\hline \multirow{9}{*}{$\begin{array}{c}\text { Effect of } \\
\text { activity on } \\
\text { behaviour }\end{array}$} & & Intensiveness (expend) $\rightarrow$ Intention to return & & & & & 0.047 & n.s. & 0.033 & n.s. \\
\hline & & Intensiveness (time) $\rightarrow$ Intention to return & & & & & -0.029 & n.s. & -0.141 & $* *$ \\
\hline & & Extensiveness $\rightarrow$ Intention to return & & & & & -0.055 & n.s. & 0.128 & $*$ \\
\hline & & Intensiveness (expend) $\rightarrow$ Recommendation & & & & & -0.064 & n.s. & -0.065 & n.s. \\
\hline & & Intensiveness (time) $\rightarrow$ Recommendation & & & & & 0.034 & n.s. & $-\mathbf{0 . 1 3 5}$ & $* *$ \\
\hline & & Extensiveness $\rightarrow$ Recommendation & & & & & -0.047 & n.s. & 0.173 & $* *$ \\
\hline & & Intensiveness (expend) $\rightarrow$ Intensification & & & & & 0.020 & n.s. & -0.027 & n.s. \\
\hline & & Intensiveness (time) $\rightarrow$ Intensification & & & & & 0.019 & n.s. & $-\mathbf{0 . 1 1 3}$ & $*$ \\
\hline & & Extensiveness $\rightarrow$ Intensification & & & & & -0.001 & n.s. & 0.249 & $* * *$ \\
\hline $\begin{array}{c}\text { Goodness of } \\
\text { fit }\end{array}$ & & & & & $\begin{array}{r}\chi^{2}(14)= \\
(\mathrm{p}=.0 \\
\mathrm{GFI}=0 \\
\text { AGFI }= \\
\mathrm{NFI}=0 \\
\mathrm{CFI}=0 \\
\text { RMSEA }\end{array}$ & $\begin{array}{l}6.328 \\
00) \\
977 \\
.873 \\
963 \\
971 \\
=0.087\end{array}$ & $\begin{array}{r}\chi^{2}(5)= \\
(\mathrm{p}=.0 \\
\mathrm{GFI}=0 \\
\mathrm{AGFI}= \\
\mathrm{NFI}=0 \\
\mathrm{CFI}=0 \\
\text { RMSEA }\end{array}$ & $\begin{array}{l}6.16 \\
00) \\
981 \\
.709 \\
970 \\
972 \\
0.144 \\
\end{array}$ & \multicolumn{2}{|c|}{$\begin{array}{c}\chi^{2}(1)=50.58 \\
(\mathrm{p}=.000) \\
\text { GFI }=0.967 \\
\text { AGFI }=0.079 \\
\text { NFI }=0.888 \\
\text { CFI }=0.885 \\
\text { RMSEA }=0.353\end{array}$} \\
\hline
\end{tabular}

(***) $\mathrm{p}<0.001 ;(* *) \mathrm{p}<0.01 ;(*) \mathrm{p}<0.05$.

(a) Standardized Coefficients; (b) $0=$ Spanish; $1=$ Foreign 
Table 4. Indirect effects

\begin{tabular}{cccc}
\hline & \multicolumn{3}{c}{ Dependent variables } \\
\cline { 2 - 4 } Independent variables & Intention to return & Recommendation & Intensification \\
\hline Intensiveness $($ expenditure) & -0.001 & 0.012 & -0.018 \\
\hline Intensiveness $($ time $)$ & $-0.094^{* *}$ & $-0.140^{* * *}$ & $-0.094^{* *}$ \\
\hline Extensiveness & $0.159^{* * *}$ & $0.200^{* * *}$ & $0.185^{* * *}$ \\
\hline$(* * *) \mathrm{p}<0.001 ;(* *) \mathrm{p}<0.01 ;(*) \mathrm{p}<0.05$ & &
\end{tabular}


Table 5. Estimation of quadratic effects of intensiveness on experience

\begin{tabular}{|c|c|c|c|c|c|c|c|c|c|}
\hline \multirow{4}{*}{$\begin{array}{l}\text { Lineal } \\
\text { effect }\end{array}$} & \multirow{4}{*}{$\begin{array}{c}\text { Expenditure } \\
R^{2} \\
\end{array}$} & \multicolumn{8}{|c|}{ Dependent variables } \\
\hline & & \multicolumn{2}{|c|}{ Attainment } & \multicolumn{2}{|c|}{ Learning } & \multicolumn{2}{|c|}{ Escapism } & \multicolumn{2}{|c|}{ Fantasy } \\
\hline & & $0.176 * * *$ & - & $0.175^{* * *} *$ & - & $0.119 * *$ & - & 0.025 & \\
\hline & & 0.031 & - & 0.031 & - & 0.014 & - & 0.001 & \\
\hline \multirow{3}{*}{$\begin{array}{l}\text { Quadratic } \\
\text { effect }\end{array}$} & Expenditure & $0.475^{* *}$ & - & $0.735 * * *$ & - & $0.380 * *$ & - & $-0.405 * *$ & - \\
\hline & Expenditure $^{2}$ & $-0.310 *$ & - & $-0.582 * * *$ & - & -0.271 & - & $0.447 * *$ & - \\
\hline & $R^{2}$ & 0.038 & & 0.055 & & 0.020 & & 0.015 & \\
\hline \multirow{2}{*}{$\begin{array}{l}\text { Lineal } \\
\text { effect }\end{array}$} & Time & - & $-0.167 * * *$ & - & -0.092 & - & -0.054 & - & -0.045 \\
\hline & $R^{2}$ & - & 0.028 & - & 0.008 & - & 0.003 & - & 0.002 \\
\hline \multirow{3}{*}{$\begin{array}{l}\text { Quadratic } \\
\text { effect }\end{array}$} & Time & - & $-0.302 * * *$ & - & 0.070 & - & -0.001 & - & 0.076 \\
\hline & Time $^{2}$ & - & 0.156 & - & $-0.188 *$ & - & -0.061 & - & -0.141 \\
\hline & $R^{2}$ & & 0.034 & & 0.017 & & 0.004 & & 0.007 \\
\hline
\end{tabular}

(***) $\mathrm{p}<0.01 ;(* *) \mathrm{p}<0.05 ;(*) \mathrm{p}<0.10$ (a) Standardized Coefficients. 